\title{
Dermatologic Extrahepatic Manifestations of Hepatitis C
}

\author{
Bhavtosh Dedania* and George Y. Wu \\ Department of Medicine, Division of Gastroenterology-Hepatology, University of Connecticut Heath Center, Farmington, CT, USA
}

\begin{abstract}
Hepatitis C virus (HCV) affects millions of people worldwide, and an estimated 3.2 million people in the United States. HCV is a hepatotropic and lymphotropic virus that causes not only liver disease, but also a significant number of extrahepatic manifestations (EHMs). Up to $74 \%$ of patients affected by $\mathrm{HCV}$ will have HCV-related EHMs of some severity in their lifetime. The EHMs vary from simple cutaneous palpable purpura to complex lymphoproliferative disorders, including lymphomas and immune-complex deposit diseases causing local and/or systemic complications. Mixed cryoglobulinemia (MC) is manifested by multiple systemic organ involvement, mainly skin, kidney, peripheral nerves, and salivary glands, and less frequently causes widespread vasculitis and malignant lymphoma. MC affects up to $3 \%$ of HCV-infected patients with cryoglobulinemia of clinical significance, i.e. $>6 \%$. Severe disease requires immunosuppressive or plasma exchange therapy. HCV prevalence in the United States in patients with porphyria cutanea tarda (PCT) was reported to be $66 \%$, much higher than that in general population. Therefore, all patients with PCT should be screened for HCV. The skin rash of PCT varies from large blisters to small vesicles and/or milia on the hands. Skin manifestations due to PCT usually respond to anti-HCV treatment together with reducing skin sun exposure, avoiding triggers, having routine phlebotomy (especially for people with chronic iron overload states), and using chloroquine. Lichen planus (LP), which typically affects both the skin and oral mucosa is a chronic inflammatory disease of squamous cell origin affecting about $1 \%$ of the worldwide population. The prevalence of HCV in patients with LP varies based on geographic location. We review here the basic pathophysiology, clinical features, and management of dermatologic manifestations of HCV.

(c) 2015 The Second Affiliated Hospital of Chongqing Medical University. Published by XIA \& HE Publishing Ltd. All rights reserved.
\end{abstract}

Keywords: Dermatologic manifestations; Extra-hepatic manifestations; Hepatitis $C$ virus; Cryoglobulinemia; Porphyria cutanea tarda; Lichen planus.

Abbreviations: AASLD, American Association for the Study of Liver Disease; CG, cryoglobulins; DAA, directly acting antiviral; EHMs, extra-hepatic manifestations; $\mathrm{HCV}$, hepatitis C virus; HFE, High Iron Fe; IFN, interferon; Ig, immunoglobulin; LP, lichen planus; MC, mixed cryoglobulinemia; MCS, MC syndrome; MPGN, membranoproliferative glomerulonephritis; $\mathrm{PCT}$, porphyria cutanea tarda; RF, rheumatoid factor; RNA, ribonucleic acid; SVR, sustained virologic response; UROD, uroporphyrinogen decarboxylase.

Received: 11 March 2015; Revised: 24 April 2015; Accepted: 26 April 2015 DOI: $10.14218 / \mathrm{JCTH} .2015 .00010$.

*Correspondence to: Bhavtosh Dedania, Department of Medicine, University of Connecticut Health Center, 263 Farmington Ave, Farmington, CT 06030, USA. Tel: +1-267-475-0383, Fax: +1-860-679-4613, E-mail: dedania@uchc.edu

\section{Introduction}

Hepatitis C virus (HCV) affects approximately 130 to 170 million people worldwide, with an estimated 3.2 million people infected in the United States. ${ }^{1-3}$ Globally, approximately 350,000 deaths each year are attributed to liver disease. ${ }^{2,3}$ Hepatitis $C$ was discovered in 1989 and was shown to be a single stranded ribonucleic acid (RNA) virus belonging to a flaviviridae group. HCV is a hepatotropic and lymphotropic virus that causes not only hepatic manifestations, but also a significant number of extra-hepatic manifestations (EHMs). Approximately $74 \%$ of patients with hepatitis $C$ will have HCV-related EHMs of some severity in their lifetime. ${ }^{4}$ The development of various EHMs by HCV likely involves autoimmune mechanisms, as evidenced by the appearance of autoimmune features, such palpable purpura, complex lymphoproliferative disorders (e.g. lymphomas), and immunecomplex deposit diseases that cause local and/or systemic complications. ${ }^{4,5}$ Among the EHMs, dermatologic manifestations significantly add to morbidity and the overall cost burden on the health care system. ${ }^{6}$ This article focuses on the basic pathophysiology, clinical features, and management of the most common dermatologic manifestations of HCV.

\section{Classification of EHMs associated with HCV}

Classification of EHMs associated with HCV is based on the available literature (Table 1).

\section{Mixed cryoglobulinemia (MC)}

\section{Introduction}

MC is the most common dermatologic EHM and was first described in $1966 .^{7}$

\section{Pathophysiology}

MC is a systemic vasculitis caused by the deposition of circulating immune complexes in the small vessels. It is manifested by multiple organ involvement, mainly skin, kidney, peripheral nerves, and salivary glands, and less frequently causes widespread vasculitis and malignant lymphoma. ${ }^{1}$ The vasculitis is associated with the presence of serum cryoglobulins (CG) which are insoluble at temperatures below $37^{\circ} \mathrm{C}$, but can dissolve by warming are responsible for MC (Fig. 1).

\section{Classification}

According to Brouet et al., ${ }^{8}$ CG can be classified based on the type of immune complex deposition. Type I is purely 
Table 1. Classification of EHMs associated with HCV

A. Significant prevalence, consistent pathogenetic data, and "ex-adjuvantibus" criteria.

- Mixed cryoglobulinemia/cryoglobulinaemic vasculitis ${ }^{7}$

- B cell non-Hodgkin's lymphoma (NHL) ${ }^{4}$

B. Higher prevalence than controls

- Porphyria cutanea tarda 23

- Lichen planus ${ }^{33,35,36}$

- Sicca syndrome

- Auto-antibody productions (rheumatoid factor, cryoglobulins, anti-smooth muscle)

- Glomerulonephritis ${ }^{12}$

C. Possible association ${ }^{2,16}$

- Polyarthritis

- Pruritus

- Fibromyalgia

- Chronic polyradiculoneuropathy

- Lung alveolitis

D. Anecdotal association ${ }^{2}$

- Polymyositis and dermatomyositis

- Psoriasis

- Erythema nodosum

E. Association with antiviral treatment (interferon alpha) ${ }^{2}$

- Hypo-hyperthyroidism

- Sarcoidosis

- Lichen planus ${ }^{36}$

- Skin vasculitis

monoclonal components. Type II is a mixture of polyclonal immunoglobulin IgG and monoclonal IgM, while Type III is a mixture of polyclonal IgG and polyclonal IgM. In MC, the IgM consists of autoantibodies with rheumatoid factor (RF) activity. MC Type II accounts for $50-60 \%$ of CGs, and Type III CG account for about $40-50 \%$ of CGs. ${ }^{1}$

\section{Clinical features}

The most common symptoms of MC syndrome (MCS) are weakness, arthralgias, and purpura, also called Meltzer's triad. ${ }^{9}$ The dermatologic manifestations of MC can vary from simple cutaneous palpable purpura (Fig. 2A) to complex confluent lesions (Fig. 2B), including ulcerations of the skin (Fig. 2C).

\section{Laboratory findings}

Ninety percent of patients with $\mathrm{MC}$ have anti-HCV AB. ${ }^{10}$ The presence of serum mixed CGs, high RF levels, and reduced complement $\mathrm{C} 4$ levels are all consistent with MC. It may be difficult to detect CGs because of their thermolability and the variability of the rate in which CGs are responsible for vasculitic damage. ${ }^{7,11}$

\section{Treatment and discussion}

The frequency of cryoglobulinemia in HCV-positive patients varies. This variability might be related to the duration of HCV

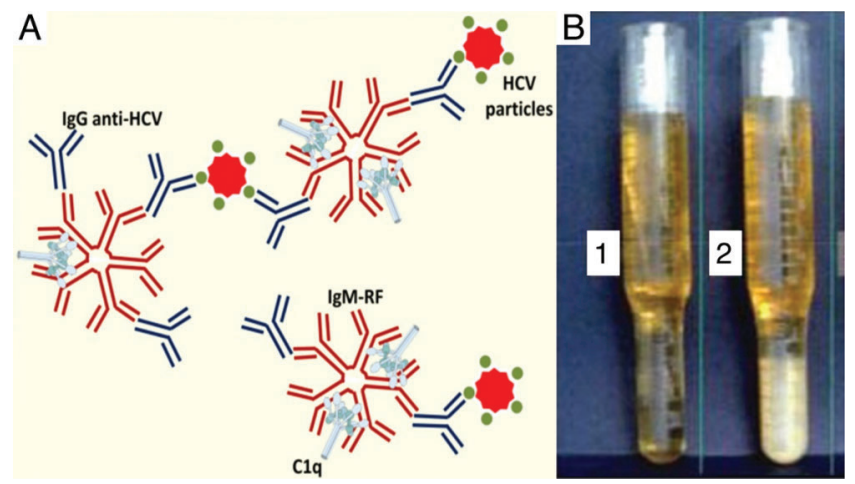

Fig. 1. A, A diagram showing polyvalent IgM binding HCV-IgG complexes to form aggregates; (Adapted from: Lauletta G. HCV, Mixed Cryoglobulinemia and Malignant Lymphoproliferation. In: Serviddio G, ed. Practical Management of Chronic Viral Hepatitis. InTech: 2013. $)^{45}$ B, Tube 1, shortly after blood draw. Tube 2, after $\mathbf{7} \mathrm{d}$ at $4{ }^{\circ} \mathrm{C}$ with precipitated CG. (Adapted from: Ferri C. Mixed Cryoglobulinemia. Orphanet J Rare Dis 2008;3:25. $)^{46}$

infection and the stage of liver fibrosis. ${ }^{7}$ Among all causes of MC, $80 \%$ of $\mathrm{MC}$ is due to $\mathrm{HCV}$, and it is usually associated with Type II CG, ${ }^{12}$ less commonly with Type III, and rarely with Type I. Patients with chronic hepatitis C and CG can present at various stages of liver fibrosis, but a higher incidence of cirrhosis and stage of fibrosis has been reported in patients with significant cryoglobulinemia $(>6 \%) .1{ }^{1,13}$ Twenty percent of patients with $\mathrm{HCV}$ have $\mathrm{MC}$, but most had $<6 \% \mathrm{CG}$, which is not clinically significant. Only $3 \%$ of HCV patients had clinically significant MCS with $>6 \%$ levels of CG. ${ }^{2}$ The mean cryocrit levels in HCV patients was $2 \% .{ }^{14}$ Renal involvement due to MCS and age $>60$ at the time of diagnosis have been linked to worse outcomes. ${ }^{15}$ Renal involvement due to cryoglobulinemia and HCV tends to present with membranoproliferative glomerulonephritis (MPGN). ${ }^{12,16}$ Severe, life threatening complications were observed in up to $10 \%$ of the patients with $\mathrm{MC}$, and the mortality ranged from 20-80\%. Mortality increased with systemic involvement, especially when there was evidence of pulmonary hemorrhage, gastrointestinal ischemia, or cardiac or central nervous system involvement. $7,15,17,18$

An algorithm for the treatment for MCS associated with $\mathrm{HCV}$ is depicted in Fig. 3. In the past, MC due to HCV was treated with standard anti-HCV therapy plus ribavirin. However, severe disease may require immunosuppressive or plasma exchange therapy. Because of the lymphotropic nature ${ }^{4}$ of $\mathrm{HCV}, \mathrm{MC}$ affects $\mathrm{B}$ cell lymphocytes in peripheral blood, liver infiltrates, and bone marrow. Rituximab (monoclonal antibody against CD20-expressing $B$ cells) has been used in refractory MCS with or without multisystem involvement.

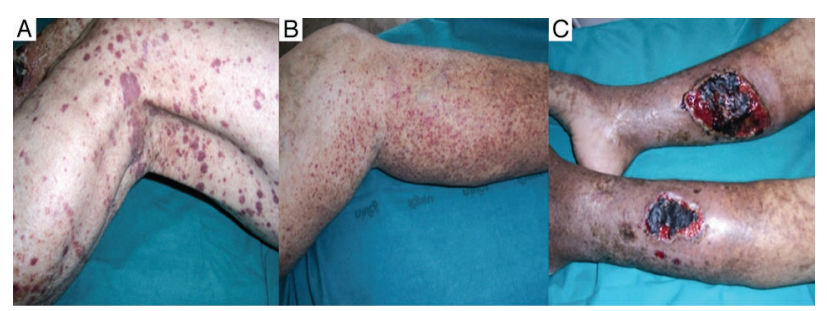

Fig. 2. A, Cutaneous palpable purpura; B, Complex confluent purpura; C, Ulcerations of skin due to cryoglobulinemic purpura. ${ }^{45}$ 
Dedania B. et al: Skin conditions associated with $\mathrm{HCV}$

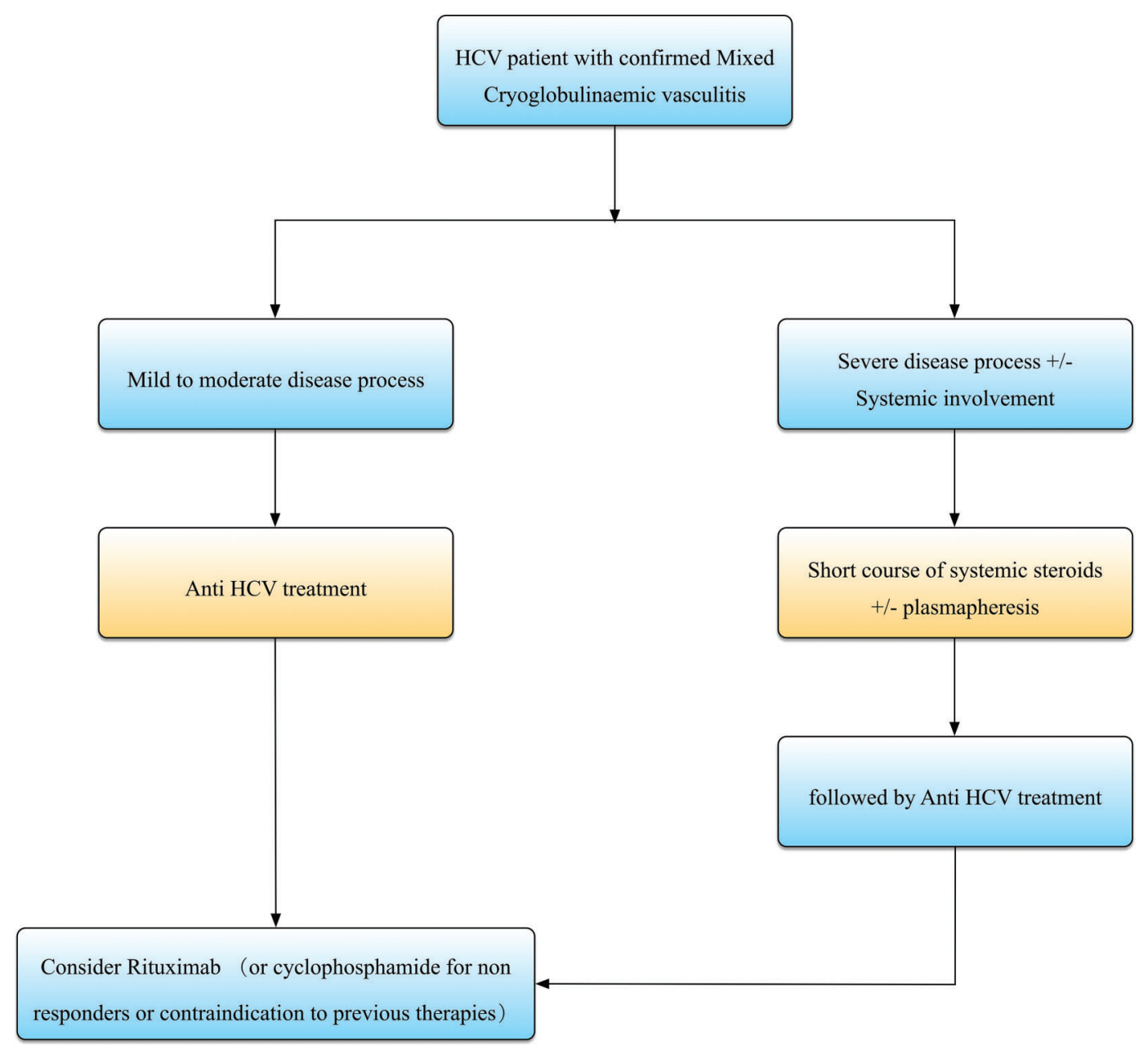

Fig. 3. A treatment algorithm for mixed CG syndrome depending on the severity of MC. ${ }^{7}$ Patients with confirmed MC and HCV with mild symptoms are treated with standard anti-HCV treatment (DAA's). However, if severe or refractory to anti-HCV treatment immunosuppressant's or plasmapheresis is recommended.

The strategy is to decrease the expansion of B cells, a likely source of CG that failed to respond to standard anti-HCV treatment. $^{5}$ Because interferon (IFN) may stimulate the immune system, thereby causing further damage in severe or advanced cases of MCS, IFN-free anti-HCV regimens are recommended. ${ }^{19} \mathrm{~A}$ thorough review of the literature has failed to identify immunohistochemistry studies regarding the change in skin lesion status after IFN therapy. However, a recent study by Saadoun et al. showed that the use of combination pegylated IFN $\alpha$ with ribavirin and a protease inhibitor seemed to be highly effective in treating HCV-related MC. ${ }^{20}$

Dermatologic manifestations of MC respond to the treatment and clearance of $\mathrm{HCV}^{21}$ Patients who relapse after initial clearance of HCV usually have relapses in their vasculitis that parallel the return of viremia. ${ }^{20}$

In summary, treatment of HCV should not be deferred due to the presence of $\mathrm{MC}$ and vasculitis. ${ }^{22}$ Because of the involvement of $\mathrm{HCV}$ in the development of MC, treatment of $\mathrm{HCV}$ alone generally improves mild to moderate MC. Because of the potential for exacerbating MC, IFN-based regimens are not recommended as anti-HCV treatment. When an IFNbased anti-HCV regimen is required, concurrent immunosuppression may be necessary. In severe MC with multisystem involvement, immunosuppressive therapy is recommended with rituximab-based regimens with or without plasmapheresis prior to initiation of anti-HCV therapy.

\section{Porphyria cutanea tarda (PCT)}

\section{Introduction}

Porphyrias are a group of rare inherited or acquired disorders of enzymes that normally participate in the production of heme and porphyrins. Porphyrias generally manifest with either neurological or skin problems or occasionally both. The term 'porphyria' is of Greek origin and meaning purplish pigment, relating to the color of porphyrins.

\section{Classification}

There are many types of porphyrias, including PCT, hereditary coproporphyria, and variegate porphyria. PCT is the most common type of porphyria and is further categorized in two different subtypes: familial and sporadic. ${ }^{23}$ In the familial form, the enzyme defect is present in hepatocytes and other cells, such as erythrocytes; whereas in the sporadic (more 
common) form, the enzyme activity is decreased to $50 \%$, affecting predominantly hepatocytes. ${ }^{24}$

\section{Pathophysiology}

There are three possible mechanisms by which PCT may develop. The basic defect in PCT is either decreased or absent activity of the enzyme uroporphyrinogen decarboxylase (UROD). Since UROD normally converts uroporphyrinogen into coproporphyrinogen in the heme-biosynthetic pathway, disruption of this pathway may cause PCT. ${ }^{14,15}$ The second mechanism is an increase in the rate or tendency of uroporphyrinogen to be oxidized to uroporphyrin. The rate of oxidation is influenced by many factors, including chronic hepatitis C, long-term alcohol intake, cytochrome P-4501A2, metabolically active iron within the hepatocytes, and estrogens. This mechanism is likely the key link among PCT, chronic liver disease, and iron overload states. The third mechanism is an increase in activity of hepatic 5-aminolevulinic acid synthase, the first and normally the rate-controlling enzyme of heme synthesis. An increase in activity of this enzyme can result in increased levels of uroporphyrinogen in hepatocytes. Oxidation of uroporphyrinogen to uroporphyrin and other nonporphyrin products can inhibit UROD. ${ }^{9,25}$

$\mathrm{HCV}$ increases iron stores, which in turn inhibit UROD. This occurs when the activity of UROD decreases to $<25 \%$ of normal levels and results in an accumulation of uroporphyrin and other carboxylated porphyrins in various organs, including the skin and liver. This increase of porphyrins predisposes skin to a photochemical reaction upon exposure to sunlight and causes the typical skin manifestations of PCT. ${ }^{25}$ Iron also increases the oxidation of uroporphyrinogen to uroporphomethene, which decreases UROD by competitive inhibition. In the presence of uroporphyrin, photo-activation of the complement system leads to activation of mast cells and proteases, and this causing dermal-epidermal splitting (Fig. 4). ${ }^{25,26}$

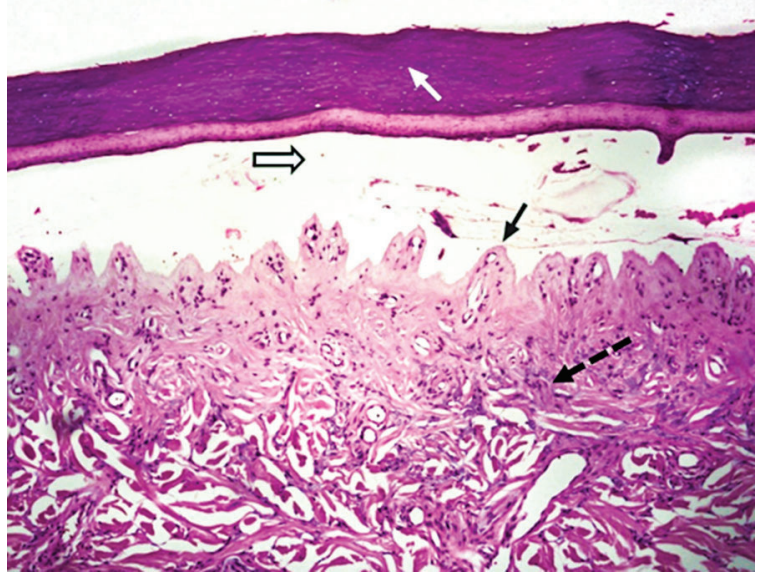

Fig. 4. Thickened stratum corneum, solid white arrow, and blister fluid separating dermal layers, hollow arrow, expanded dermal papillae, solid black arrow, and fibrosis and sclerodermoid skin changes, dashed arrow. (Reproduced from: Zakko L, Finch J, Rothe MJ, Grant-Kels JM. Hepatitis C Virus: Dermatological features. In: Grant-Kels JM, Selsky N, Wu GY, eds. Atlas of Dermatological Manifestations of Gastrointestinal Disease. Springer: 2013,167-169. $)^{47}$

\section{Clinical features}

PCT is frequently found in middle-aged men who have a history of chronic liver disease either due to chronic iron overload states, heavy alcohol abuse, or HCV.

The earliest manifestation of PCT is a skin rash that varies from large blisters, small vesicles, and/or milia on the dorsal aspect of the hands (Fig. 5). ${ }^{27}$ Other manifestations include increased skin fragility, hypertrichosis (especially involving lateral aspect of the face), chronic hyper/hypopigmentation, chloracne, sclerodermoid changes, dystrophic calcifications with ulcerations, scarring, alopecia, and onycholysis. Patients can also manifest stigmata of advanced liver disease and cirrhosis if the latter is present.

\section{Treatment}

Treatment consists of controlling sun exposure of the skin, avoiding triggers, getting routine phlebotomy (especially in cases of chronic iron overload), and using chloroquine. Patients with PCT should stop alcohol consumption and estrogen and iron supplementation. For patients with underlying $\mathrm{HCV}$ manifesting with PCT, treating the underlying cause with IFN-based anti-HCV treatment has been reported to result in resolution of PCT lesions. Currently, however, there are no clinical trials or data available on whether treatment of HCV infection and acheivement of sustained virologic response (SVR) with directly acting antiviral (DAA) agents improves PCT. The cornerstone of the treatment still largely depends on routine phlebotomy and controlling the triggers. Based on the American Association for the Study of Liver Disease (AASLD) guidelines for HCV treatment, PCT is class IIB, level C rating, and newer DAAs are recommended for this condition. Based on the guidelines, achievement of an SVR with DAAs should result in resolution of PCT-related dermatological manifestations.

\section{Discussion}

In a meta-analysis by Gisbert et al. that included 50 studies (2,167 patients), the mean prevalence of $\mathrm{HCV}$ antibodies and positive HCV RNA in patients with $\mathrm{PCT}$ was estimated to be $47 \%(95 \% \mathrm{CI}=45-49 \%)$ and $50 \%(95 \% \mathrm{CI}=47-53 \%)$, respectively. Furthermore, when considering only casecontrol studies in which anti-HCV antibodies and/or HCV RNA by polymerase chain reaction were performed, a tight

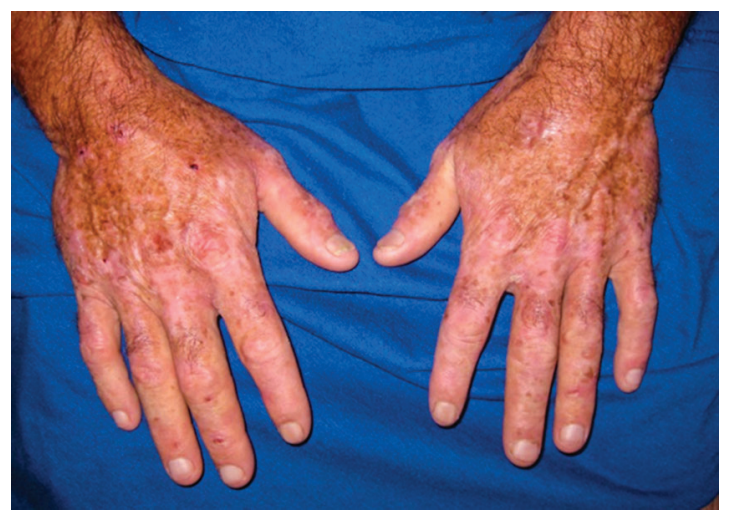

Fig. 5. Dermatologic blisters and hyperpigmentation findings in porphyria cutanea tarda seen in sun-exposed areas. ${ }^{47}$ 
association was found between PCT and HCV infection (OR= 82). The prevalence of HCV infection was significantly higher in the sporadic form of PCT $(57 \%, 95 \% \mathrm{CI}=5-75 \%)$ than in the familial form $(26 \%, 95 \% \mathrm{CI}=17-34 \%)$. HCV prevalence in patients in the United States with PCT was reported to be approximately $66 \%$, much higher than that reported in the general population. Therefore, all patients with PCT should be screened for HCV. However, among the HCV-infected population, the overall prevalence of PCT was estimated to be less than $5 \%{ }^{26}$ and as low as $1 \% .^{2}$ Since the chance of having $\mathrm{HCV}$ infection is higher in patient with $\mathrm{PCT}$, all patients with PCT should be screened for HCV infection. ${ }^{24}$ The prevalence of HFE gene mutations in North American patients with PCT is high. It is, therefore, recommended to screen for HFE mutations and $\mathrm{HCV}$ infection in patients who present with PCT. ${ }^{27,28}$

To summarize, patients who are diagnosed with PCT should be screened for HCV because of the association between the two. Only $1-5 \%$ of patients with HCV will have evidence of $\mathrm{PCT}^{29}$ The skin lesions of PCT respond to standard anti-HCV and PCT therapies.

\section{Lichen planus}

\section{Introduction}

Lichen planus (LP) is a chronic inflammatory disease that affects skin and mucous membranes of squamous cell origin. LP affects about $1 \%$ of the general population, and it is a common disorder affecting stratified squamous epithelia, particularly of the oral cavity. ${ }^{30}$

\section{Pathophysiology}

Although the exact pathophysiology of LP remains unknown, one potential mechanism is induction of keratinocyte apoptosis by cytotoxic CD8+T cells, stimulated by unidentified triggers $^{31}$ or autoimmune antibodies. The histopathological features of dermal LP lesions exhibit an irregular sawtooth appearance suggestive of epidermal hyperplasia (Fig. 6), deep compact hyperkeratosis with wedge-shaped thickening of the granular cell layer, and a dense band-like T-cell infiltrate obscuring the dermal-epidermal junction.

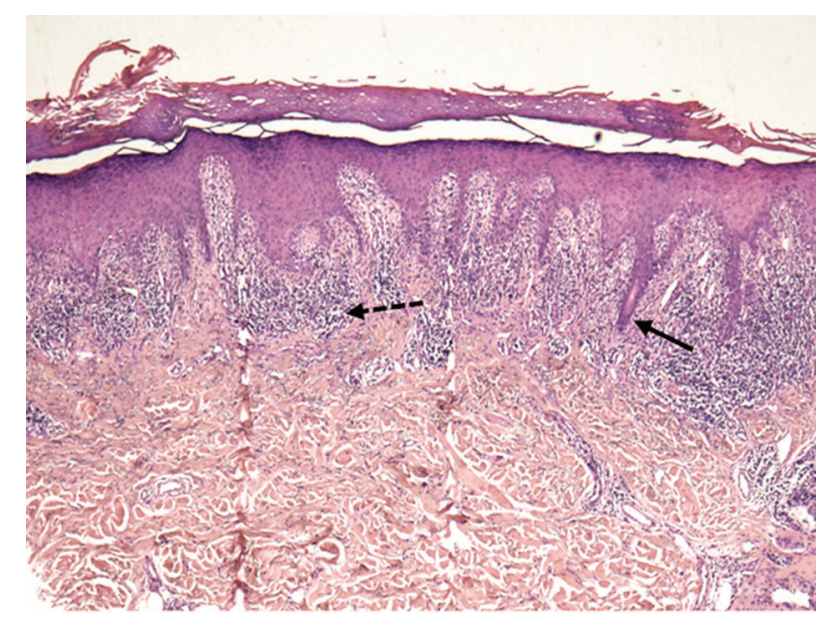

Fig. 6. Histopathology of lichen planus. Black solid arrow showing a saw tooth pattern of epidermal hyperplasia, dashed arrow showing band of $T$ cell infiltrate. ${ }^{47}$

\section{Clinical features}

LP typically affects women between the ages of 30 and $60 .^{31}$ Lesions in the mucous membrane usually present as white lace-like Wickham's striae, which are found in the lateral buccal mucosa, involving sometimes the lips, gingivae, and tongue (Fig. 7A). ${ }^{27}$ On the skin, LP usually presents as purplish, flat-topped papules and intensely pruritic, polygonal lesions on the flexor aspect of wrists and forearms, extensor aspect of hands and ankles, lumbar region, shins, and genital area (Fig. 7B). ${ }^{27}$

\section{Treatment}

Symptoms of LP are usually treated with either topical or injectable steroids. To date, data on the response to IFN treatment are inconsistent, as both improvement and exacerbation of symptoms have been reported. ${ }^{32}$ There are strong data demonstrating that treatment of underlying $\mathrm{HCV}$ with anti-HCV treatment, especially IFN-based regimens, may not lead to regression of all LP lesions. ${ }^{33}$ At this time, there are no convincing data on the response of LP to DAAs. ${ }^{34}$ Other treatment options have been reported, such as topical calcineurin inhibitors, phototherapy, systemic retinoids, and methotrexate. For pruritus due to the dermal lesions, oral antihistamines have bene reported to provide symptomatic relief.

\section{Discussion}

A potential connection between hepatitis viruses and LP is shown by the frequent association between LP and chronic liver disease. ${ }^{35.36}$ Given the odds ratio and prevalence figures in various countries, it has been estimated that the prevalence of HCV in patients with LP varies from $4 \%$ in Europe to $24 \%$ in the Middle East. ${ }^{37,38}$ With the advent of sensitive HCV diagnostic tests, a rise in the number of case reports, cohort, and controlled studies occurred, further supporting a link between $\mathrm{LP}$ and HCV. ${ }^{39}$ A study compared the prevalence of HCV antibodies in 263 patients with oral LP to a control group of 100 patients who were receiving routine dental care. Twenty-nine percent of those with LP tested positive for HCV antibodies, compared to only $3 \%$ in the control group. ${ }^{40}$ However, others have shown that $2 \%$ of $127 \mathrm{HCV}$-positive patients had oral LP, and only one in 24 consecutive patients with LP was anti-HCV seropositive. ${ }^{41} \mathrm{~A}$ recent study suggested a weak or no association between HCV infection and LP. ${ }^{42}$ The possible explanation for this significant difference could be the low endemicity
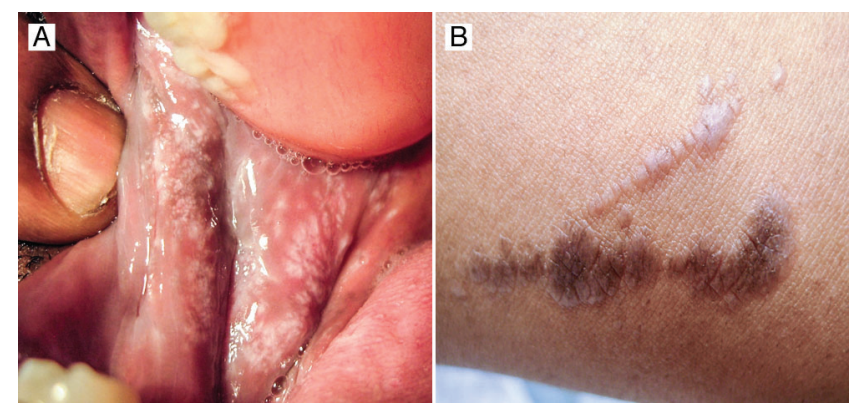

Fig. 7. Mucosal and dermatologic involvement of lichen planus (LP). A, mucosal white lace like 'Wickham's striae"; B, shows purplish polygonal papules showing skin involvement of LP. ${ }^{47}$ 
of HCV in India and differences in HCV genotype (3a and 3b are more common in India, while genotypes 1 and 2 are more common in America and Europe). ${ }^{42}$

In summary, $\mathrm{HCV}$ infection contributes to almost $2 \%$ of all LP cases, but routine HCV testing of all LP patients is not indicated. ${ }^{43}$ The main reason for identifying and treating $L P$ lesions is to prevent malignant transformation of the lesions. ${ }^{31}$ There has been evidence to suggest that low levels of vitamin $D$ in patients with chronic HCV infections may lead to a higher incidence of EHMs. ${ }^{44}$

\section{Conclusions}

HCV causes numerous hepatic as well EHMs. Treating the underlying HCV with anti-HCV therapy, ribavirin with or without interferon has led to significant improvements in some EHMs.

\section{Conflict of interest}

None.

\section{Author contributions}

Writing the article (BD), conceiving the idea and editing the manuscript (GYW).

\section{References}

[1] Saadoun D, Asselah T, Resche-Rigon M, Charlotte F, Bedossa P, Valla D, et al. Cryoglobulinemia is associated with steatosis and fibrosis in chronic hepatitis C. Hepatology 2006;43:1337-1345. doi: 10.1002/hep.21190.

[2] Cacoub P, Gragnani L, Comarmond C, Zignego AL. Extrahepatic manifestations of chronic hepatitis C virus infection. Dig Liver Dis 2014;46(Suppl): S165-S173. doi: 10.1016/j.dld.2014.10.005.

[3] Wasley A, Alter MJ. Epidemiology of hepatitis C: geographic differences and temporal trends. Semin Liver Dis 2000;20:1-16.

[4] Zignego AL, Giannini C, Monti M, Gragnani L. Hepatitis C virus lymphotropism: lessons from a decade of studies. Dig Liver Dis 2007;39(Suppl), S38-S45. doi: 10.1016/S1590-8658(07)80009-0.

[5] Ramos-Casals M, Font J. Extra hepatic manifestations in patients with chronic hepatitis C virus infection. Curr Opin Rheumatol 2005;17:447-455.

[6] Younossi ZM, Stepanova M, Mishra A, Venkatesan C, Henry L, Hunt S. The impact of chronic hepatitis $C$ on resource utilization and in-patient mortality for Medicare beneficiaries between 2005 and 2010. Aliment Pharmacol Ther 2013;38:1065-1075. doi: 10.1111/apt.12485.

[7] Ramos-Casals M, Stone JH, Cid MC, Bosch X. The cryoglobulinaemias. Lancet 2012;379:348-360. doi: 10.1016/S0140-6736(11)60242-0.

[8] Brouet JC, Clauvel JP, Danon F, Klein M, Seligmann M. Biologic and Clinical Significance of Cryoglobulins. A report of 86 cases. Am J Med 1974;57: $775-788$.

[9] Sène D, Limal N, Cacoub P. Hepatitis C Virus-Associated Extrahepatic Manifestations: A Review. Metab Brain Dis 2004;19:357-381.

[10] Güngör E, Cirit A, Alli N, Karakayali G, Gür G, Artüz F. Prevalence of Hepatitis $C$ Virus Antibodies and Cryoglobulinemia in Patients with Leukocytoclastic Vasculitis. Dermatology 1999;198:26-28. doi: 10.1159/000018059.

[11] Fallahi P, Ferri C, Ferrari SM. The Emerging Extra Hepatic Manifestations of Hepatitis C Virus Infection in Chronic Hepatitis and Mixed Cryoglobulinemia. Hepat Mon 2008;8:207-211.

[12] Ko HM, Hernandez-Prera JC, Zhu H, Dikman SH, Sidhu HK, Ward SC, et al. Morphologic Features of Extrahepatic Manifestations of Hepatitis C Virus Infection. Clin Dev Immunol 2012;2012:740138. doi: 10.1155/2012/740138.

[13] Stefanova-Petrova DV, Tzvetanska AH, Naumova EJ, Mihailova AP, Hadjiev EA, Dikova RP, et al. Chronic hepatitis $C$ virus infection: Prevalence of extra hepatic manifestations and association with Cryoglobulinemia in Bulgarian patients. World J Gastroenterol 2007;13:6518-6528. doi: 10.3748/wjg.v13. i48.6518.

[14] Hadziyannis SJ. The spectrum of extra hepatic manifestations in hepatitis C virus infection. J Viral Hepat 1997;4:9-28.

[15] Terrier B, Semoun O, Saadoun D, Sène D, Resche-Rigon M, Cacoub P. Prognostic Factors in Patients with Hepatitis $C$ Virus Infection and Systemic vasculitis. Arthritis Rheum 2011;63:1748-1757. doi: 10.1002/art.30319.
[16] Khattab MA, Eslam M, Alavian SM. Hepatitis C Virus as a Multifaceted Disease: A Simple and Updated Approach for Extrahepatic Manifestations of Hepatitis C Virus Infection. Hepat Mon 2010;10:258-269.

[17] Ramos-Casals M, Robles A, Brito-Zerón P, Nardi N, Nicolás JM, Forns $X$, et al. Life-threatening Cryoglobulinemia: Clinical and Immunological Characterization of 29 Cases. Semin Arthritis Rheum. 2006;36:189-196. doi: 10.1016/j. semarthrit.2006.08.005.

[18] Paredes AH, Torres DM. Extra hepatic Manifestations of Hepatitis C Virus Infection: Mixed Cryoglobulinemia and Beyond. Curr Hepatol Rep 2011;10: 11-18. doi: 10.1007/s11901-010-0062-2.

[19] Jadali Z. Dermatologic Manifestations of Hepatitis C Infection and the Effect of Interferon Therapy: A Literature Review: Zohreh Jadali. Dermatologic Manifestations of Hepatitis C Infection and the Effect of Interferon Therapy: A Literature Review. Arch Iran Med 2012;15:43-48. doi: $012151 /$ AIM.0012.

[20] Saadoun D, Resche Rigon M, Thibault V, Longuet M, Pol S, Blanc F, et al. PegIFN $\alpha /$ ribavirin/protease inhibitor combination in hepatitis $C$ virus associated mixedcryoglobulinemia vasculitis: results at week 24. Ann Rheum Dis 2014;73: 831-837. doi: 10.1136/annrheumdis-2012-202770.

[21] Misiani R, Bellavita P, Fenili D, Vicari O, Marchesi D, Sironi PL, et al. Interferon Alfa-2a Therapy in Cryoglobulinemia Associated with Hepatitis C Virus. N Engl J Med 1994;330:751-756. doi: 10.1056/NEJM199403173301104.

[22] Nishida N, Kudo M. Clinical Features of Vascular Disorders Associated with Chronic Hepatitis Virus Infection. Dig Dis 2014;32:786-790. doi: 10. $1159 / 000368023$.

[23] Chuang TY, Brashear R, Lewis C. Porphyria cutanea tarda and hepatitis C virus: A case-control study and meta-analysis of the literature. J Am Acad Dermatol 1999;41:31-36. doi: 10.1016/S0190-9622(99)70402-0.

[24] Gisbert JP, García-Buey L, Pajares JM, Moreno-Otero R. Prevalence of hepatitis $C$ virus infection in porphyria cutanea tarda: systematic review and meta-analysis. J Hepatol 2003;39:620-627. doi: 10.1016/S0168-8278 (03)00346-5.

[25] Bonkovsky HL, Mehta S. Hepatitis C: A review and update. J Am Acad Dermatol 2001;44:159-182.

[26] Bonkovsky HL, Poh-Fitzpatrick M, Pimstone N, Obando J, Di Bisceglie A, Tattrie C, et al. Porphyria Cutanea Tarda, Hepatitis C, and HFE Gene Mutations in North America. Hepatology 1998;27:1661-1669. doi: 10.1002/hep. 510270627.

[27] Remoroza R, Wu GY. Extra hepatic manifestations of chronic hepatitis C. Chin J Dig Dis 2003;4:93-99. doi: 10.1046/j.1443-9573.2003.00131.x.

[28] Ryan Caballes F, Sendi H, Bonkovsky HL. Hepatitis C, porphyria Cutanea Tarda and liver iron: an update. Liver Int 2012;32:880-893. doi: 10. $1111 / j .1478-3231.2012 .02794 . x$

[29] Tsukazaki N, Watanabe M, Irifune H. Porphyria Cutanea Tarda and hepatitis C virus infection. $\mathrm{Br}$ ] Dermatol 1998;138:1015-1017. doi: 10.1046/j.13652133.1998.02269.x.

[30] Eisen D, Carrozzo M, Bagan Sebastian JV, Thongprasom K. Number V Oral lichen planus: clinical features and management. Oral Dis 2005;11:338349. doi: $10.1111 /$ j.1601-0825.2005.01142.x.

[31] Farhi D, Dupin N. Pathophysiology, etiologic factors, and clinical management of oral lichen planus, part I: facts and controversies. Clin Dermatol 2010;28: 100-108. doi: 10.1016/j.clindermatol.2009.03.004.

[32] Mayo MJ. Extra hepatic Manifestations of Hepatitis C Infection. Am J Med Sci 2003;325:135-148.

[33] Petti S, Rabiei M, De Luca M, Scully C. The magnitude of the association between hepatitis $C$ virus infection and oral lichen planus: meta-analysis and case control study. Odontology 2011;99:168-178. doi: 10. 1007/s10266-011-0008-3.

[34] Gumber SC, Chopra S. Hepatitis C: a multifaceted disease. Review of Extrahepatic manifestations. Ann Intern Med 1995;123:615-620. doi: 10. 7326/0003-4819-123-8-199510150-00008.

[35] Mokni M, Rybojad M, Puppin D Jr, Catala S, Venezia F, Djian R, et al. Lichen planus and hepatitis C virus. J Am Acad Dermatol 1991;24:792.

[36] Lodi G, Pellicano R, Carrozzo M. Hepatitis C virus infection and lichen planus: a systematic review with meta-analysis. Oral Dis 2010;16:601-612. doi: 10 1111/j.1601-0825.2010.01670.x

[37] Bigby M. The Relationship between Lichen Planus and Hepatitis C Clarified. Arch Dermatol 2009;145:1048-1050. doi: 10.1001/archderm.145.9.1048.

[38] Al-Nasser L, El-Metwally A. Oral lichen planus in Arab countries: a Review. J Oral Pathol Med 2014;43:723-727. doi: 10.1111/jop.12136.

[39] Carrozzo M. Oral diseases associated with hepatitis C virus infection Part 2. Lichen planus and other diseases. Oral Dis 2008;14:217-228. doi: 10 . $1111 /$ j.1601-0825.2007.01432.x.

[40] Mignogna MD, Fedele S, Lo Russo L, Ruoppo E, Adamo D, Lo Muzio L. Extra hepatic manifestations of Hepatitis $C$ virus infection: the slowly unraveling picture of oral lichen planus. J Hepatol 2002;37:412-413. doi: 10. 1016/S0168-8278(02)00173-3.

[41] Grote M, Reichart PA, Berg T, Hopf U. Hepatitis C virus (HCV) -infection and oral lichen planus. J Hepatol 1998;29:1034-1035. doi: 10.1016/S01688278(98)80139-6. 
[42] Kumar KPM, Jois HS, Hallikerimath S, Kale AD. Oral Lichen Planus as an Extra-hepatic Manifestation of Viral Hepatitis-Evaluation in Indian Subpopulation. J Clin Diagn Res 2013;7:2068-2069. doi: 10.7860/JCDR/2013/5731. 3407.

[43] Al-Hashimi I, Schifter M, Lockhart PB, Wray D, Brennan M, Migliorati CA, et al. Oral lichen planus and oral lichenoid lesions: diagnostic and therapeutic considerations. Oral Surg Oral Med Oral Pathol Oral Radiol Endod 2007;103(Suppl):S25.e1-e12. doi: 10.1016/j.tripleo.2006. 11.001.

[44] Terrier B, Jehan F, Munteanu M, Geri G, Saadoun D, Sène D, et al. Low 25hydroxyvitamin D serum levels correlate with the presence of extra-hepatic manifestations in chronic hepatitis $C$ virus infection. Rheumatology (Oxford) 2012;51:2083-2090. doi: 10.1093/rheumatology/kes209.

[45] Lauletta G. HCV, Mixed Cryoglobulinemia and Malignant Lymphoproliferation. In: Serviddio G, ed. Practical Management of Chronic Viral Hepatitis. InTech: 2013. doi: 10.5772/55474.

[46] Ferri C. Mixed Cryoglobulinemia. Orphanet J Rare Dis 2008;3:25. doi: 10. 1186/1750-1172-3-25

[47] Zakko L, Finch J, Rothe MJ, Grant-Kels JM. Hepatitis C Virus: Dermatological features. In: Grant-Kels JM, Selsky N, Wu GY, eds. Atlas of Dermatological Manifestations of Gastrointestinal Disease. Springer: 2013,167-169. doi: 10.1007/978-1-4614-6191-3_64. 